\title{
Human Papilloma Virus Epidemiology and Subtyping in Head and Neck Squamous Cell Carcinoma by Anatomical Site in Central Greece
}

\author{
Melina Tsea ${ }^{1}$, Vasileios Lachanas ${ }^{1}$, Zoi Florou ${ }^{2}$, Anargyros Skoulakis ${ }^{2}$, Stergios Doumas ${ }^{1}$, John Chatziioannou ${ }^{1}$, \\ Efthymia Petinaki ${ }^{1}$ and Charalampos Skoulakis ${ }^{1 *}$ \\ ${ }^{1}$ ENT Department, University Hospital of Larissa, Mezourlo, Larissa, Greece \\ ${ }^{2}$ Department of Microbiology, University Hospital of Larissa, Mezourlo, Larissa, Greece \\ Submission: May11, 2018; Published: June 11, 2018 \\ *Corresponding author: Charalampos Skoulakis, University Hospital of Larissa, Mezourlo, Larissa, Greece, Tel: (+) 30693 3352005; \\ Fax: 00302413501036; Email: skulakis@hotmail.com/cskoulakis@med.uth.gr
}

\begin{abstract}
Objectives: To assess Human Papilloma Virus (HPV) prevalence and subtypes distribution in a population of Head and Neck Squamous cell carcinoma (HNSCC) patients in Central Greece.

Methods: Paraffin-embedded biopsy samples from 90 patients with confirmed HNSCC, were retrospectively analysed for the presence of various HPV sub-types via real time PCR. In addition, a total of 206 controls, who visited the ENT Department the same period, were also tested for the presence of HPV sub-types in their pharyngeal cavity, by the same molecular assay.

Results: According to the anatomical site, HNSCC originated from four different sites: oral cavity, oropharynx, larynx, and hypopharynx. The presence of HPV was detected in $42.2 \%$ of samples (38/90), while the most prevalent subtype was HPV-16 (89.5\%; 34/38), followed by HPV-18 (\%), HPV-31 and HPV-33(\%). Amongst the HPV(+) HNSCC samples, most originated from the oral cavity $(45 \%, 17 / 38)$ and the oropharynx (32\%, 12/38). On the other hand, among the non-HNSCC controls, 9.7\% (20/206) were HPV positive, while the most prevalent sub-types were HPV-31, HPV-56, HPV-45 and HPV-41 (Table 1); moreover, six samples were positive for more one subtypes. Statistical analysis revealed that HPV (+) patients were 7 times more likely to have HNSCC [OR 6.8, 95\%CI 3.65-12.67, p<0.0005], and HPV-16 (+) patients were 124 times more likely to have HNSCC [OR 124.5, 95\%CI 16.67-929.3, p<0.0005].
\end{abstract}

Conclusion: High prevalence of HPV was detected in HNSCC patients in Central Greece, where HPV-16 predominate. Our results demonstrate the necessity of the 9-valent HPV vaccination.

Keywords: Hnscc; Human Papilloma Virus; Human Papilloma Virus subtypes; Human Papilloma Virus Epidemiology

\section{Introduction}

Human papilloma virus (HPV)-associated cancer accounts for $5 \%$ of all cancers worldwide [1,2], and for $29.5 \%$ of new cancer cases attributable to infections [3]. HPVs are DNA virus that infect epithelial cells [4]. More than 207 HPV -subtypes have been identified so far, and their association with tumour progression has been under research for more than 50 years [4,5]. 40 HPV subtypes infect the anogenital tract, and within these, there are oncogenic HPV subtypes which are classified as either high-risk, causing intraepithelial neoplasia and cervical cancers (HPVs 16, 18, 31, 33, 35, 39, 45, 51, 52, 56, 58, 59, 68, 73,82 ), or low-risk, causing genital warts (HPVs 6,11 ) [4]. HPV 16 and HPV 18 together account for $70 \%$ of cervical cancers [6].

The first evidence for an association between HPV and head and neck squamous cell carcinoma (HNSCC) was published in the 1980s [7,8], while, many more publications followed [9-12].
Global epidemiological data indicate that oral HPV infection is one of the main causes for the dramatic increase in oropharyngeal cancer that has controversially been characterized as epidemic $[13,14]$.

The oropharynx is the main site of HPV-associated HNSCC, and, to a lesser extent the oral cavity and larynx [15]. 90\% of oral cavity, pharyngeal, and laryngeal cancers are squamous cell carcinomas [16]. HPV -16 is the subtype most commonly associated with HNSCC, present in more than $80 \%$ of cases $[13,17]$.

Alcohol and tobacco abuse are the commonest risk factors for these malignancies [16]. However, patients with HNSCC who are also positive for HPV-associated disease are less likely to abuse alcohol and tobacco and are usually younger than HPV-negative subjects $[18,19]$. Furthermore, HPV (+) patients show a better 
response to treatment and better survival outcome [16,20], and HPV status detection has been suggested as independent predictor of overall survival [21].

Globally, the geographical distribution of HNSCC is diametrically different: the incidence of cervical cancer is higher in the less developed world, while the incidence of head and neck cancer is highest in North America and Europe [15]. Epidemiology data on HPV infection in Greece mostly focus on cervical cancer [22-24], and a recent systematic review revealed a data gap regarding HPV prevalence on oropharyngeal sites [24]. In Greece, no data exist concerning the prevalence of HPV in HNSCC. Aim of the present study was to assess HPV-subtypes prevalence in a population of HNSCC patients in Central Greece between 2010-2014.

\section{Methods}

\section{Setting}

HNSCC samples: We used retrospectively paraffinembedded tumour samples from patients who had undergone surgery for HNSCC between 2010-2014. Only Squamous Cell Carcinoma (SCC) samples were included in our analysis that was accompanied by a complete histological analysis and a complete patient history.

Non-HNSCC samples: Pharyngeal swab samples were collected from individuals (93 men and 113 women) 12-80 years old, all habitants of Central Greece, with clinically normal mouth mucosa who had visited our ENT Department between 2010-2014, and were tested for HPV-subtypes by the same molecular method mentioned above. All participants provided written informed consent, and completed a questionnaire with demographic data (age, sex, occupation, residence, behavior, HPV-vaccination etc). The protocol was approved by the Ethics Committee of the University Hospital of Larissa, Greece (N 3450).

\section{HPV-Subtypes Molecular Detection}

All paraffin and pharyngeal samples were sent to the Microbiology Laboratory of the University Hospital of LarissaGreece for further analysis. Extraction of total DNA was assessed using commercial kits (Invitrogen), according to the manufacturer's instructions. The efficiency of DNA extraction and the possible presence of inhibitors in the sample were confirmed by the detection of $\beta 2$-globin gene. The extracted DNA samples were tested by quantitative real-time PCR (Applied Biosystems 7500 Fast Real-Time PCR system) according to the manufacturer's instructions, using two commercially available assays, the HPV High Risk Screen Real Time PCR (Sacace Biotechnologies), which detects the sub-types 16, 18, 31, 33, 35, $39,45,51,52,56,58,59,66,68$ and the HPV 6/11 Real-Time PCR kit [25-27].

\section{Statistical Analysis}

The chi-square test, Fisher's exact test, or independent t-test was used as appropriate for the comparison of demographics between HPV $(+)$ and HPV (-) samples. The risk of HPV infection was estimated using logistic regression. The statistical package SPSS version 14.00 (SPSS Inc, Chicago, IL) was used for all statistical analyses. All tests were two-sided. The level of statistical significance was set at $\mathrm{P}<0.005$.

\section{Results}

\section{HPV Prevalence and Subtype Identification}

A total of 90 HNSCC, originated from four different sites (oral cavity, oropharynx, larynx and hypopharynx) and 206 nonHNSCC samples were included. According to the data obtained, $42.2 \%$ (38/90) of HSCNN samples were HPV (+), most of which (89.5\%; 34/38) were positive for the HPV-16 subtype (Table 1); three samples positive for HPV-16 were also positive either HPV-6 or HPV-11. Among the 38 HPV-positive HNSCC, 17 (45\%) originated from the oral cavity, 12 (32\%) from oropharynx, 5 (13\%) from larynx and 4(10\%) from hypopharynx (Table 2 describes the distribution of HPV-subtypes in each anatomical site). Sex, smoking status, and alcohol use did not differ statistically significantly between HPV (+) and HPV (-) HNSCC patients (Table 3).

Table 1: HPV subtype detection and comparison between HNSCC $(\mathrm{N}=90)$ and Non-HNSCC $(\mathrm{N}=206)$ samples.

\begin{tabular}{|c|c|c|c|}
\hline & $\begin{array}{c}\text { HNCCCgroup } \\
(\mathbf{N}=\mathbf{9 0})\end{array}$ & $\begin{array}{c}\text { Non-HNSCC } \\
(\mathbf{N}=\mathbf{2 0 6})\end{array}$ & $\mathbf{P}$ \\
\hline HPV positive & 38 & 20 & - \\
\hline HPV 16 & 34 & 1 & $<0.0005$ \\
\hline HPV 18 & 1 & 3 & 1.000 \\
\hline HPV 31 & 1 & 7 & 0.442 \\
\hline HPV 33 & 1 & 2 & 1.000 \\
\hline HPV 39 & 0 & 3 & 0.556 \\
\hline HPV 45 & 0 & 4 & 0.318 \\
\hline HPV 51 & 0 & 4 & 0.318 \\
\hline HPV 56 & 0 & 5 & 0.328 \\
\hline HPV 58 & 0 & 1 & 1.000 \\
\hline HPV 59 & 0 & 3 & 1.000 \\
\hline HPV 6 or 11 & 4 & 0 & 0.014 \\
\hline
\end{tabular}

Table 2 : HPV subtype distribution by HNSCC anatomical site.

\begin{tabular}{|c|c|c|c|c|}
\hline & Larynx & Oropharynx & Hypopharynx & $\begin{array}{c}\text { Oral } \\
\text { cavity }\end{array}$ \\
\hline HPV 16 & 5 & 11 & 4 & 14 \\
\hline HPV 18 & 0 & 0 & 0 & 1 \\
\hline HPV 31 & 0 & 1 & 0 & 0 \\
\hline HPV 33 & 0 & 0 & 0 & 1 \\
\hline HPV 6, 11 & 0 & 2 & 0 & 2 \\
\hline
\end{tabular}


Table 3: Comparison of demographic characteristics of HPV (+) and HPV (-) amongst the HNSCC patients ( $\mathrm{N}=90)$.

\begin{tabular}{|c|c|c|c|}
\hline & HPV (+) & HPV (-) & P \\
\hline $\mathrm{n},(\%)$ & $38(42.2)$ & $52(57.8)$ & \\
\hline $\begin{array}{c}\text { Age, mean, } \\
\text { (SD) }\end{array}$ & $61(14)$ & $61(12)$ & 0.851 \\
\hline Male & 30 & 42 & 1.000 \\
\hline Female & 8 & 10 & \\
\hline Smoking & 21 & 30 & 0.833 \\
\hline Alcohol & 15 & 16 & 0.501 \\
\hline
\end{tabular}

On the other hand, $9.7 \%$ of non-HNSCC control samples (20/206) were HPV (+), where the most prevalent subtypes were HPV-31, HPV-56, HPV-45 and HPV-41 (Table 1); among them, six samples were positive for more than one subtypes. It is interesting that the HPV-16 was only detected only in one sample of this group.

According to the questionnaire obtained, none of the HNSCC and non-HNSCC patients was vaccinated by the tetra-valent HPV vaccine. HPV (+) sub-types were found significantly more frequently in the HNSCC samples than in the non-HNSCC samples (42.2\% vs. $10 \%, \mathrm{p}<0.0005)$. The same was found for HPV $16(+)$ (37.8\% vs. $0.5 \%, \mathrm{p}<0.0005)$ and for HPV 6 and $11(+)$ (4.4\% vs. $0 \%, \mathrm{p}=0.014$ ) (Table 1).

\section{Logistic Regression Results}

Statistical analysis revealed that HPV (+) samples were 7 times more likely to have HNSCC [OR 6.8, 95\%CI 3.65-12.67, $\mathrm{p}<0.0005]$, and samples positive for HPV 16 were 124 times more likely to have HNSCC [OR 124.5, 95\%CI 16.67-929.3, $\mathrm{p}<0.0005]$. Dependence on the site of the HNSCC, oropharynx samples were 10.2 times more likely to be HPV (+) and 187.9 times more likely to be HPV -16 (+) (Table 4).

Table 4: Logistic regression results for the likelihood of HPV or HPV 16 infection,

\begin{tabular}{|c|c|c|c|c|}
\hline & \multicolumn{2}{|c|}{ HPV (+) } & \multicolumn{2}{c|}{ HPV 16 (+) } \\
\hline & $\begin{array}{c}\text { Odds } \\
\text { Ratio } \\
(\mathbf{9 5 \%}\end{array}$ & P value & $\begin{array}{c}\text { Odds Ratio } \\
\mathbf{( 9 5 \% C I )}\end{array}$ & P value \\
\hline \multirow{3}{*}{ Oropharynx } & $\begin{array}{c}10.2(3.97- \\
25.95)\end{array}$ & $<0.0005$ & $\begin{array}{c}187.9 \\
(22.37- \\
1578.56)\end{array}$ & $<0.0005$ \\
\hline \multirow{2}{*}{ Oral cavity } & $\begin{array}{c}7.5(3.42- \\
16.56)\end{array}$ & $<0.0005$ & $\begin{array}{c}119.6 \\
(15.05- \\
949.91)\end{array}$ & $<0.0005$ \\
\hline \multirow{2}{*}{ Hypopharynx } & $\begin{array}{c}6.2(1.61- \\
23.83)\end{array}$ & 0.008 & $\begin{array}{c}136.7 \\
(13.21-\end{array}$ & $<0.0005$ \\
\hline Larynx & $3.32(1.08-$ & 0.036 & $73.2(8.00-$ & $<0.0005$ \\
\hline
\end{tabular}

HNSCC vs. Non-HNSCC.

\section{Discussion}

According to our results, high prevalence of HPV (42.2\%) was detected in patients with HNSCC in Central Greece, a rural Greek area with 1.000.000 inhabitants. We note that approximately twenty/ thirty patients per year admitted to the ENT Department of University Hospital of Larissa-Greece are diagnosed with HNSCC. The HPV prevalence in our HNSCC samples was quite similar to the $40.0 \%$ HPV prevalence reported in a metaanalysis of 39 studies conducted in 19 European countries [28]. The prevalence differed according to the anatomical sites, e.g. was $66.4 \%$ in tonsillar cancers, $25.7 \%$ in tongue cancers, and $15.3 \%$ in pharyngeal cancers [28]. A systematic review of 105 studies conducted in 23 countries in Europe and North America investigated HPV prevalence in oropharyngeal squamous cell carcinoma [29]. The study reported an increasing trend in HPV prevalence in the European countries from 28\% before 1995 to $49.5 \%$ after 2005 [29]. However, data from other Greek studies demonstrate lower HPV prevalence in HNSCC: $22.2 \%$ $(14 / 63)$ reported by Blioumi et al and $11.1 \%$ (5/45) reported by Kouvousi et al $[30,31]$. This variation could be explained by the method used which varies between in situ hybridization to PCR, immunohistochemistry or Southern blot [25,31]. Geographical variations have also been reported to affect HPV HNSCC prevalence rates. For example, in the North-East Italy Baboci et al reported $8.5 \%$ prevalence for HPV DNA in 247 HNSCC cases [32]. In India, Bahl et al reported $22.8 \%$ HPV prevalence in oropharyngeal patients [33]. In Nigeria, Oga et al did not detect HPV in Head Neck Carcinoma (HNC) patients [34]. In Senegale, Ndiaye et al reported very low prevalence (3.4\%) [17] while, similar prevalence was reported by Ribeiro et al in samples collected from Argentina, Brazil, Cuba, Russia, Slovakia, Czech republic, Romania, and Poland [35]. On the contrary, in France, St Guily et al reported $46.5 \%$ HPV prevalence, in oropharyngeal carcinomas [36]. In South Wales (UK), Evans et al detected 55\% HPV DNA [37].

On the other hand, among non-HNSCC individuals the prevalence of HPV in the pharynx was $9.7 \%$, while various highrisk subtypes were identified $(16,18,31,33,39,45,51,56,58$ and 59). In the USA, an oral HPV prevalence study conducted as part of the US National Health and Nutrition Examination Survey (NHANES) found that $6.9 \%$ of men and women between 14-69 years of age were HPV (+) [38]. Since HPV-16 predominate in HNSCC samples, only one sample was found to be positive in non-HNSCC group.

In conclusion, $42.2 \%$ of patients with HNSCC were HPV (+), whereas, HPV- 16 was the most common subtype detected. Given the rapidly increasing incidence of oropharyngeal cancer and its association with HPV infection, more research in this area would assist in the formulation of appropriate disease surveillance interventions. Furthermore, our data emphasizes the need for a wide vaccination of Greek people by the 9-valent HPV vaccine that includes the subtypes $6,11,16,18,31,33,45,52$, and 58 [38].

\section{References}

1. deSanjose S, Brotons M, Pavon MA (2018) The natural history of human papillomavirus infection. Best Pract Res Clin Obstet Gynaecol 47: 2-13. 


\section{Global Journal of Otolaryngology}

2. Hellner K, Dorrell L (2017) Recent advances in understanding and preventing human papillomavirus-related disease. F1000Res 6: 269.

3. Plummer M, de MC, Vignat J, Ferlay J, Bray F, et al. (2016) Global burden of cancers attributable to infections in 2012: a synthetic analysis. Lancet Glob Health 4(9): e609-e616.

4. Graham SV (2017) The human papillomavirus replication cycle, and its links to cancer progression: a comprehensive review. Clin Sci (Lond) 131(17): 2201-2221.

5. (2017) The Nobel Prize in Physiology or Medicine.

6. Lowy DR, Schiller JT (2012) Reducing HPV-associated cancer globally. Cancer Prev Res (Phila) 2; 5(1): 18-23.

7. Syrjanen KJ, Pyrhonen S, Syrjanen SM, Lamberg MA (1983) Immunohistochemical demonstration of human papilloma virus (HPV) antigens in oral squamous cell lesions. Br J Oral Surg 21(2): 147-153.

8. IARC Working Group on the Evaluation of Carcinogenic Risk to Humans (1995) Human papillomaviruses. IARC 64: 1-378.

9. Shi W, Kato H, Perez-Ordonez B, Pintilie M, Huang S, et al. (2009) Comparative prognostic value of HPV16 E6 mRNA compared with in situ hybridization for human oropharyngeal squamous carcinoma. J Clin Oncol 27(36): 6213-6221.

10. Chaturvedi AK, Engels EA, Pfeiffer RM, Hernandez BY, Xiao W, et al. (2011) Human papillomavirus and rising oropharyngeal cancer incidence in the United States. J Clin Oncol 29(32): 4294-4301.

11. Pytynia KB, Dahlstrom KR, Sturgis EM (2014) Epidemiology of HPVassociated oropharyngeal cancer. Oral Oncol 50(5): 380-386.

12. Spence T, Bruce J, Yip KW, Liu FF (2016) HPV Associated Head and Neck Cancer. Cancers (Basel) 8(8): 75.

13. Gillison ML, Chaturvedi AK, Anderson WF, Fakhry C (2015) Epidemiology of Human Papillomavirus-Positive Head and Neck Squamous Cell Carcinoma. J Clin Oncol 33(29): 3235-3242.

14. Rietbergen MM, Leemans CR, Bloemena E, Heideman DA, Braakhuis BJ, et al. (2013) Increasing prevalence rates of HPV attributable oropharyngeal squamous cell carcinomas in the Netherlands as assessed by a validated test algorithm. Int J Cancer 132(7): 1565-1571

15. deMartel C, Plummer M, Vignat J, Franceschi S (2017) Worldwide burden of cancer attributable to HPV by site, country and HPV type. Int J Cancer 141(4): 664-670.

16. Adelstein D, Gillison ML, Pfister DG, Spencer S, Adkins D, et al. (2017) NCCN Guidelines Insights: Head and Neck Cancers, Version 2.2017. Natl Compr Canc Netw 15(6): 761-770.

17. Ndiaye C, Mena M, Alemany, Arbyn M, Castellsagué X, L et al. (2014) HPV DNA, E6/E7 mRNA, and p16INK4a detection in head and neck cancers: a systematic review and meta-analysis. Lancet Oncol 15(12): $1319-1331$.

18. O'Sullivan B, Huang SH, Siu LL, Waldron J, Zhao H, et al. (2013) Deintensification candidate subgroups in human papillomavirusrelated oropharyngeal cancer according to minimal risk of distant metastasis. J Clin Oncol 31(5): 543-550.

19. Goon PK, Stanley MA, Ebmeyer J , Steinsträsser L, Upile T, et al. (2009) HPV \& head and neck cancer: a descriptive update. Head Neck Oncol $1: 36$.

20. Ang KK, Harris J, Wheeler R, Weber R, Rosenthal DI, et al. (2010) Human papillomavirus and survival of patients with oropharyngeal cancer. N Engl J Med 363(1): 24-35.

21. Fakhry C, Zhang Q Nguyen-Tan PF, Rosenthal D, El-Naggar A, et al. (2014) Human papillomavirus and overall survival after progression of oropharyngeal squamous cell carcinoma. J Clin Oncol 32(30): 33653373.
22. Agorastos T, Chatzistamatiou K, Zafrakas M, Siamanta V, Katsamagkas T, et al. (2014) Epidemiology of HPV infection and current status of cervical cancer prevention in Greece: final results of the LYSISTRATA cross-sectional study. Eur J Cancer Prev 23(5): 425-431.

23. Agorastos T, Lambropoulos AF, Sotiriadis A, Mikos T, Togaridou E, et al. (2009) Prevalence and distribution of high-risk human papillomavirus in Greece. Eur J Cancer Prev 18(6): 504-509.

24. Tsikis S, Hoefer L, Charnot-Katsikas A, Schneider JA (2016) Human papillomavirus infection by anatomical site among Greek men and women: a systematic review. Eur J Cancer Prev 25(6): 558-571.

25. Zaravinos A, Mammas IN, Sourvinos G, Spandidos DA (2009) Molecular detection methods of human papillomavirus (HPV). Int J Biol Markers 24(4): 215-222.

26. Florou Z, Pantelidi K, Serafim F, Skoulakis A, Petinaki E, et al. (2018) Prevalence of Sexually Transmitted Infections (STIs) in asymptomatic Greek women. Arch Clin Microbiol 9(2): 78.

27. Skoulakis A, Lachanas V, Florou Z, Samara M, Mantzana-Petinelli M, et al. (2018) High-Prevalence of various high-risk sub-types of Human Papilloma Virus in patients with acquired cholesteatoma in Greece. Acta Scientific Microbiology 1(4): 03-05.

28. Abogunrin S, Di Tanna GL, Keeping S, Carroll S, Iheanacho I (2014) Prevalence of human papillomavirus in head and neck cancers in European populations: a meta-analysis. BMC Cancer 14: 968.

29. Stein AP, Saha S, Kraninger JL, Swick AD, Yu M, et al. (2015) Prevalence of Human Papillomavirus in oropharyngeal cancer: A Systematic Review. Cancer J 21(3): 138-146.

30. Blioumi E, Chatzidimitriou D, Pazartzi C, Katopodi T, Tzimagiorgis G, et al. (2014) Detection and typing of human papillomaviruses (HPV) in malignant, dysplastic, nondysplastic and normal oral epithelium by nested polymerase chain reaction, immunohistochemistry and transitional electron microscopy in patients of northern Greece. Oral Oncol 50(9): 840-847.

31. Kouvousi M, Xesfyngi D, Tsimplaki E, Argyri E, Ioannidou G, et al (2013) Prevalence of human papillomavirus in 45 Greek patients with oral cancer. J Oncol 2013: 756510.

32. Baboci L, Holzinger D, Boscolo-Rizzo P, Tirelli G, Spinato R, et al. (2016) Low prevalence of HPV-driven head and neck squamous cell carcinoma in North-East Italy. Papillomavirus Res 2: 133-140

33. Bahl A, Kumar P, Dar L, Mohanti BK, Sharma A, et al. (2014) Prevalence and trends of human papillomavirus in oropharyngeal cancer in a predominantly north Indian population. Head Neck 36(4): 505-510.

34. Oga EA, Schumaker LM, Alabi BS, Obaseki D, Umana A, et al. (2016) Paucity of HPV-related Head and Neck Cancers (HNC) in Nigeria. PLoS One 11(4): e0152828.

35. Ribeiro KB, Levi JE, Pawlita M, Koifman S, Matos E, et al. (2011) Low human papillomavirus prevalence in head and neck cancer: results from two large case-control studies in high-incidence regions. Int J Epidemiol 40(2): 489-502.

36. St Guily JL, Jacquard AC, Pretet JL, Haesebaert J, Beby-Defaux A, et al (2011) Human papillomavirus genotype distribution in oropharynx and oral cavity cancer in France--The EDiTH VI study. J Clin Virol 51(2): 100-104.

37. Evans M, Newcombe R, Fiander A, Powell J, Rolles M, et al. (2013) Human Papillomavirus-associated oropharyngeal cancer: an observational study of diagnosis, prevalence and prognosis in a UK population. BMC Cancer 13: 220.

38. Gillison ML, Broutian T, Pickard RK, Tong ZY, Xiao W, et al. (2012) Prevalence of oral HPV infection in the United States, 2009-2010. JAMA 307(7): 693-703 
(C) This work is licensed under Creative DOI: 10.19080/GJO.2018.16.555927

\section{Your next submission with Juniper Publishers} will reach you the below assets

- Quality Editorial service

- Swift Peer Review

- Reprints availability

- E-prints Service

- Manuscript Podcast for convenient understanding

- Global attainment for your research

- Manuscript accessibility in different formats

( Pdf, E-pub, Full Text, Audio)

- Unceasing customer service

Track the below URL for one-step submission https://juniperpublishers.com/online-submission.php 